\title{
Los profesores y los desafíos de las diversidades y de las migraciones en España: formación y políticas educativas
}

\section{Teachers and the challenges of diversities and migration in Spain: training and educational policies}

\author{
José González-MONTEAGUDO' \\ Miriam Zamora-SERRATO²
}

\begin{abstract}
Resumen
El crecimiento del alumnado inmigrante en las aulas en Espańa es una realidad originada por el fenómeno migratorio. En este artículo, analizaremos la responsabilidad y compromiso de la escuela en atención a la diversidad intercultural. Se comenta el marco normativo espańol y el planteamiento de las políticas educativas orientadas a la inclusión. Desde el punto de vista metodológico, se han examinado documentos relativos a instituciones públicas, tercer sector e investigaciones científicas para abordar el tema de forma integral. Se destacan los desafíos del profesorado ante esta situación y cómo influye la formación para ofrecer una respuesta pedagógica adecuada. Se concluye que el profesorado demanda formación en interculturalidad para generar actitudes, valores y prácticas que promuevan la diversidad como enriquecimiento para todos/as.
\end{abstract}

Palabras claves: Migraciones. Diversidad cultural. Educación intercultural. Profesorado. España.
Abstract

The growth of immigrant pupils in the classrooms in Spain is a reality originated by the migratory phenomenon. In this article, we will analyze the school's responsibility and commitment to diversity. It traces how this challenge is included in the regulatory framework of Spain and the approach of educational policies aimed at inclusion. From the methodological point of view, documents relating to public institutions, the third sector and scientific research have been examined in order to approach the subject in a comprehensive manner. The challenges faced by teachers in this situation are highlighted, as well as the influence of training in offering an adequate pedagogical response. It is concluded that teachers demand training in interculturality in order to generate attitudes, values and practices that promote diversity as an enrichment for all.

Keywords: Migrations. Cultural diversity. Intercultural education. Teachers. Spain.

1 Profesor titular de la Universidad de Sevilla. Doctor en Pedagogía por la Facultad de Educación de la Universidad de Sevilla (España). Líneas de investigación: teorías educativas contemporáneas; procesos de enseñanza-aprendizaje; prácticas y políticas innovadoras en universidades; estudiantes universitarios no tradicionales; investigación etnográfica y biográfico-narrativa. Durante el año 2018, ha sido responsable en España de tres proyectos europeos: CAPTIVE (Violencia de género contra las mujeres inmigrantes), ELEF (Formatos de aprendizaje para la democracia y la ciudadanía) y QUAMMELOT (Educación y aprendizaje de alumnado inmigrante / Formación de profesores en línea). Email: monteagu@us.es

2 Técnica de Investigación en el Departamento de Teoría e Historia de la Educación y Pedagogía Social en la Universidad de Sevilla (España). Graduada en Pedagogía. Máster Universitario en Profesorado de Enseńanza Secundaria y Formación Profesional. Email: mzamora6@us.es

\begin{tabular}{|l|l|l|l|l|l|} 
R. Educ. Públ. & Cuiabá & v. 28 & n. 68 & p. $275-296$ & maio/ago. 2019 \\
\hline
\end{tabular}




\section{Migraciones, diversidad e interculturalidad: el contexto reciente en España ${ }^{3}$}

Las causas, impactos y consecuencias de los movimientos de población intranacionales y transnacionales se han convertido en tema de estudio recurrente en las ciencias sociales (MICOLTA-LEÓN, 2005). El fenómeno de la migración es global, complejo y cambiante. La migración afecta tanto a las personas que migran como a las personas del lugar de acogida (GUICHOTMUNOOZ; GONZÁLEZ-MONTEAGUDO, 2015). La migración se define como "el traslado se realiza de un país a otro, o de una región a otra lo suficientemente distinta, por un tiempo prolongado como para que implique vivir en otro lugar y desarrollar las actividades de la vida cotidiana" (MICOLTALEÓN, 2005, p. 61).

Desde 1990 España es uno de los países de Europa que recibe más inmigrantes. A finales de 2009, residían en España cinco millones y medio de personas extranjeras (GUICHOT-MUÑOZ; GONZÁLEZ-MONTEAGUDO, 2015). En España existía una preocupación por la integración de los extranjeros y el reconocimiento como ciudadanos. Por ello, en el año 2000 se aprueba la Ley Orgánica 4/2000, de 11 de enero, sobre derechos y libertades de los extranjeros en España y su integración social. Esta ley fue reformada en 2003 para mejorar la respuesta de atención a este colectivo (BERNABÉ-VILLODRE, 2013). Durante el periodo comprendido entre 2007 y 2012 en todas las regiones española se ha incrementado la presencia de inmigrantes. Sin embargo, según datos de 2014, casi el 70\% de las personas inmigrantes se concentraba en Cataluña, Madrid, Comunidad Valenciana y Andalucía (NIETO-MERINO, 2015). En un principio, la población española consideraba como favorable la llegada de inmigrantes y la diversidad cultural como algo enriquecedor. A partir de la crisis

3 Este artículo se deriva del Proyecto Europeo Erasmus+ QUAMMELOT (Qualification for Minor Migrants Education and Learning Open Access - Online Teacher Training. Referencia: 2017-1-IT02KA201-036610; enero de 2018 a agosto de 2020). El proyecto tiene como objetivo reforzar la profesionalidad de los docentes a través de la cooperación europea, mediante la investigación, intervención y formación para promover la integración social y educativa de los alumnos y menores de origen inmigrante en las escuelas secundarias. En este proyecto participan seis socios académicos y no académicos de cuatro países europeos: Dinamarca, España, Grecia e Italia. La coordinadora general del proyecto es la Dra. Raffaella Biagioli (Universidad de Florencia, Italia). El coordinador del proyecto en Espańa es el Dr. José González-Monteagudo (Universidad de Sevilla). La información y los puntos de vista expuestos en esta publicación son los de sus autores y no reflejan la opinión oficial de la Unión Europea. Ni las instituciones y organismos de la Unión Europea ni ninguna persona que actúe en su nombre podrá ser considerada responsable del uso que pueda hacerse de la información aquí contenida. 
económica, las actitudes durante el periodo 2008-2013 han ido cambiando. La población nativa ha comenzado a considerar que la población inmigrante es un factor de competencia en el mercado laboral (NIETO-MERINO, 2015).

Según el Instituto Nacional de Estadística, en 2017 residían en España 4.572.807 personas extranjeras, lo que representaba aproximadamente el 10\% del total de la población residente en España. Esto muestra la relevancia del fenómeno de inmigración en España. Entre enero y octubre de 2018 han llegado unos 54.000 extranjeros a España, un 146\% más que en el mismo periodo del año anterior, según datos de la Comisión Europea. El 98\% de las llegadas provenían de Marruecos. Aunque la cifra de fallecimientos en los itinerarios migratorios no se conoce con exactitud, a lo largo de 2018 casi 600 personas han muerto en la ruta hacia España, según datos de la Organización Internacional para las Migraciones, dependiente de la ONU (EL PAIIS, 2018).

En busca de soluciones, España se resiste a pedir ayuda a Europa ante el desafío migratorio, pues argumenta que lo que necesita de la Unión Europea es más fondos para los países de origen y tránsito de los flujos migratorios. Además, los movimientos migratorios han calado en el conjunto de la sociedad, así lo demuestran también los datos sobre la formación de parejas mixtas o binacionales. El fenómeno de las parejas binacionales es una consecuencia de la entrada masiva de los inmigrantes en nuestro país. Se considera matrimonio binacional al matrimonio que está formado por cónyuges de naciones diferentes. Según los datos del Instituto Nacional de Estadística (INE, 2018), en 2017 se registraron en Espańa 23.982 matrimonios mixtos, lo que supone el $15,34 \%$ del total. En este sentido, en España se habla de la nueva generación mestiza. Esta nueva situación ha favorecido la disminución de estereotipos y de prejuicios hacia la población inmigrante (RAMAJO, 2013). En agosto de 2018 la vicepresidenta del Gobierno español, Carmen Calvo, reivindicó la identidad "mestiza" de España, a la que consideró "un gran pasillo geográfico" con una "extraordinaria diversidad interna". En sus palabras: "No hay mejor educación que la cultura, ni mejor cooperación, ni mejor política internacional que la cultura, porque desde la cultura somos libres, diversos y nos podemos reconocer, encontrar y desde ella nos debemos respetar" (EUROPA PRESS, 2018). En julio de 2018, el nuevo Gobierno español del Partido Socialista aprobó la norma que recupera la sanidad universal, cumpliendo uno de sus principales compromisos, que era devolver a los ciudadanos los derechos laborales y de salud, reducidos por el gobierno del Partido Popular como estrategia para enfrentar la crisis económica. Con esta norma, los inmigrantes en situación irregular tendrán derecho a la asistencia sanitaria en igualdad de condiciones con los españoles, sin tener que justificar su residencia en España (EL MUNDO, 2018). 
Sin embargo, no todo son buenas noticias. Eurostat, la oficina europea de estadística, ha informado que España ocupa el quinto lugar por la cola en el ranking de la Unión Europea (UE) sobre tasa de empleo. En España, la tasa de empleo en 2017 fue de solo el 66,4\%, mientras que la media de la Unión Europea fue del 76,1\%. España está por delante de Grecia (56,2\%), Hungría $(58,2 \%)$, Croacia $(58,5 \%)$ y Letonia $(63,4 \%)$. En lo más alto del ranking están Chequia (86,5\%), Estonia $(85,1 \%)$ y Reino Unido (84,3\%). Como solución, la UE se ha marcado como objetivo que el $75 \%$ de los migrantes tengan trabajo en 2020. Este criterio se cumple sólo en un 9\% de las regiones europeas en cuanto a la tasa de empleo para ciudadanos no comunitarios; y en el 55\% de las regiones respecto a la tasa de empleo de ciudadanos de otros países de la UE (EXPANSIÓN, 2018). Con lo que respecta a la región de Andalucía, en el sur de Espańa, por su situación geográfica, su clima y su mercado laboral, se ha convertido en una región que ha pasado de enviar emigrantes fuera a una región de inmigración y acogida para personas de diferentes países (GOENECHEA; IGLESIAS-ALFÉREZ, 2017).

Como hemos comentado, el fenómeno de la migración provoca cambios en todos los sectores sociales. En relación a esta transformación, el proceso de integrar a esos "otros" en nuestras vidas puede atender a una de estas tres perspectivas teórico-prácticas sobre la diversidad cultural: asimilacionista, multiculturalista e interculturalista (DURÁN-MUÑOZ, 2011). Siguiendo a Besalú (2002), el asimilacionismo considera la diversidad cultural un problema y concibe la diferencia cultural como un déficit; el multiculturalismo hace referencia a la convivencia de diferentes culturas dando prioridad al grupo de pertenencia, siendo considerado el superior; el interculturalismo, finalmente, se basa en el respeto y la tolerancia por cada cultura para construir una sociedad diversa, cohesionada y democrática.

La institución educativa no ha quedado al margen de estos procesos migratorios, pues se ha producido una llegada masiva de alumnado inmigrante desde finales de los noventa del siglo pasado, y esta llegada continuó creciendo hasta el curso 2013-2014 (GOENECHEA; IGLESIASALFÉREZ, 2017). En este contexto, el objetivo del presente trabajo es reflexionar sobre las siguientes cuestiones: ¿El profesorado está formado para trabajar la diversidad cultural en el aula?; ¿Cuáles son los retos que supondrá esta situación?; ¿Cómo han evolucionado las políticas educativas para la inclusión educativa del alumnado inmigrante?

Este artículo es el resultado de una investigación cualitativa, basada en el análisis documental. Como criterio metodológico hemos seleccionado y valorado literatura científica reciente, páginas webs relevantes y documentos de 
entidades públicas, privadas y del tercer sector. El análisis documental consiste en generar un nuevo conocimiento a través de la recogida, selección y revisión de los datos. El objetivo es elaborar un nuevo documento con información más unificada y contrastada, procedente de diferentes fuentes (GÓMEZ-FERRI; GRAU-MUNOOZ; GIULIA-INGELLIS; JABBAZ, S/F; HERNÁNDEZAYALA; TOBÓN-TOBÓN, 2016).

Este artículo se deriva del Proyecto Europeo Erasmus+ QUAMMELOT (Qualification for Minor Migrants Education and Learning Open Access - Online Teacher Training. Referencia: 2017-1-IT02-KA201-036610), que se desarrolla entre enero de 2018 y agosto de 2020. El proyecto tiene como objetivo reforzar la profesionalidad de los docentes a través de la cooperación europea, mediante la investigación, intervención y formación para promover la integración social y educativa de los alumnos y menores de origen inmigrante. En este proyecto participan seis socios académicos y no académicos de cuatro países europeos: Italia, Grecia, España y Dinamarca.

La finalidad es crear un curso de formación online, denominado "Tutor de acogida e inclusión de alumnado inmigrante y menores extranjeros en escuelas secundarias", para proporcionar herramientas al profesorado para la inclusión social y educativa del alumnado inmigrante de enseñanza secundaria (12 a 18 años). Por ello, a lo largo del artículo se incluirán fragmentos de entrevistas que se han realizado a profesores y otros profesionales de la educación, en la región de Andalucía (España), que cuentan sus experiencias con el alumnado inmigrante y sus propuestas para una correcta integración social y educativa.

\section{Formación del profesorado en España. El reto de la formación intercultural}

Las escuelas actuales se han convertido en espacios de convivencia entre alumnado autóctono y alumnado inmigrante de diferente procedencia (LEIVA, 2011). Las diferentes procedencias del alumnado generan en el aula la convivencia de diferentes culturas, lo cual requiere una adecuada respuesta pedagógica. Diversas investigaciones (SORIANO, 2012; AGUADO-ODINA, 2014; AGUADED-RAMÎREZ; VILAS-BOAS; PONCE-GONZÁLEZ; RODRÍGUEZ, 2010) consideran que se debe de apostar por la educación intercultural como una respuesta a la diversidad, a través del respeto y la aceptación de las culturas presentes en la clase, el centro educativo y la sociedad en su conjunto. 
Actualmente, para pertenecer al cuerpo de profesores en España hay que acreditar un título universitario (licenciatura, ingeniería, arquitectura o título de grado correspondiente) y cursar un master homologado y obligatorio de formación del profesorado. Este master es un título profesionalizante, necesario para el ejercicio de la docencia en Enseńanza Secundaria en los centros públicos y privados del Estado español. Dependiendo de cada universidad, el master recibe un nombre diferente, siempre haciendo referencia a los términos de formación, enseñanza, profesorado o similares. En la Universidad de Sevilla recibe el título de "Master Universitario en Profesorado de Enseñanza Secundaria Obligatoria y Bachillerato y Formación Profesional”. El contenido de este master es similar a nivel nacional, siguiendo indicaciones de la normativa vigente. Este Máster se implantó en el curso 2009/2010, y amplía la formación que existía en España para capacitar al profesorado. Anteriormente se realizaba un Curso de Adaptación Pedagógica (CAP).

Este master tiene una duración de un curso académico y capacita profesionalmente al profesorado de Educación Secundaria en España. La formación de esta titulación proporciona las competencias, las destrezas y las habilidades exigidas por la normativa vigente a los futuros profesores de estos niveles educativos. El fin de este master es capacitar al futuro profesorado para que enseñe los contenidos del área del saber correspondiente al título en el que se formó previamente, actuando profesionalmente como miembro de un equipo docente, participando en el marco de una comunidad educativa ubicada en un contexto sociocultural concreto y ejerciendo de facilitador del aprendizaje del alumnado de estos niveles educativos, llegando a ser competente en las funciones tutoriales de orientación personal, académica y profesional.

Una vez que el profesorado se ha incorporado al sistema educativo formal, hay una oferta de cursos de formación permanente y de desarrollo profesional, coordinada desde los Centros de Formación del Profesorado (CEP). El problema es que desde los CEP no se realizan actuaciones específicas sobre la diversidad cultural, las migraciones, el alumnado inmigrante y los procesos de adaptación integración educativa del alumnado de origen extranjero. Actualmente, la mayoría de los cursos se refieren a las nuevas tecnologías, la innovación educativa, las metodologías activas de aprendizaje y el asesoramiento y apoyo a los centros educativos.

En España se planea la necesidad de un cambio en la formación permanente del profesorado, adaptado a las demandas de la sociedad globalizada y cambiante en la que vivimos. Sin embargo, "la educación es uno de los ámbitos sociales a los que más le cuesta cambiar" (DÍEZ-PALOMAR; FLECHA-GARCÍA, 2010, p.19). El propio profesorado lo corrobora: "Me 
parece interesante desde el punto de vista que hemos tenido alguna pequeña formación a nivel de idioma o de cultura. Yo creo que todas esas cosas siempre generan empatía en el alumno. Y eso viene muy bien" (Palabras de un Profesor de Secundaria, Sevilla, España, 2018).

Recientes investigaciones han corroborado que la formación del profesorado en educación intercultural es escasa, tanto en la formación inicial como en la permanente. Se ha incrementado la oferta formativa sobre migraciones, alumnado inmigrante, educación intercultural e inclusión educativa. Sin embargo, estas acciones formativas no consiguen implicar al profesorado, no se adquieren competencias interculturales y se tratan aspectos culturales limitados al folclore y a cuestiones estéticas. Como consecuencia de ello, el profesorado no sabe intervenir en un aula diversa, con presencia de alumnado con diferentes características y necesidades (GOENECHEA, 2016; BORREGOLÓPEZ, 2015; GOENECHEA, 2008; PEÑALVA-VELEZ; SORIANO, 2010). Según Escarbajal-Frutos y Morales-Cánovas (2016, p. 159) "no existe una interculturalización del curriculum, sino un maquillaje denominado intercultural en actividades e iniciativas escolares puntuales no imbricadas en el curriculum escolar (...) la formación intercultural no tiene sentido si no atiende a principios de respeto y comunicación".

Los planes de estudio de los grados universitarios no detallan materias propuestas con contenido, objetivo y metodología para desarrollar actitudes interculturales; en este sentido, no se puede hablar de formación permanente si previamente no ha existido formación inicial (PEÑALVA-VELEZ; SORIANO, 2010). La formación inicial universitaria es fundamental para erradicar los estereotipos, prejuicios y conductas discriminatorias relativos al alumnado inmigrante, para formar alumnos en el marco de una sociedad intercultural, democrática e inclusiva (NAVARRO-BARBA, 2015; ESCARBAJAL-FRUTOS; LEIVA, 2017). Posteriormente, desde los Centros del Profesorado se debería de promover una formación permanente de los docentes que impulse acciones formativas relacionadas con la interculturalidad, para intervenir con el alumnado inmigrante en los centros educativos mediante el análisis y la reflexión sobre la práctica escolar, de manera que sea posible cuestionar y transformar las teóricas y las prácticas de los docentes.

Un profesor que trabaja en una institución educativa para favorecer la inclusión y la interculturalidad debería de tener, como mínimo, algunas actitudes muy precisas: "compromiso con las causas de los grupos culturales marginados en defensa de la dignidad e igualdad; tolerancia horizontal activa y valoración de lo diferente; apertura al mundo, abierto a las innovaciones y a las propuestas novedosas" (ESCARBAJAL-FRUTOS, 2010, p. 171). 


\section{Legislación educativa en España: la diversidad cultural en el currículo}

"Desde el comienzo de los años noventa encontramos en Espańa una fuerte coexistencia entre la atención a la diversidad cultural, el discurso programático de la interculturalidad y el análisis de realidades escolares vinculadas a la presencia de colectivos minorizados calificados de problemáticos (...) fundamentalmente, estudios vinculados a la presencia de alumnado de origen extranjero o hijos de familias inmigrantes extranjeras" (GARCÍACANO; MÁRQUEZ-LEPE; ANTOLÍNEZ-DOMÍNGUEZ, 2016, p.254).

En 1970 se aprueba en Espańa la Ley 14/1970, de 4 de agosto, General de Educación y Financiamiento de la Reforma Educativa (LGE). En el Artículo dos se indica: "Los extranjeros residentes en España tendrán derecho a la Educación General Básica y a una formación profesional del primer grado de forma gratuita”. En el Artículo cuarenta y ocho, se dice: "Se establecerán cursos especiales para extranjeros, que permitan a éstos seguir con el máximo aprovechamiento cualquier ciclo del sistema educativo e informarse de la cultura española”. La Ley Orgánica 8/1985, de 3 de julio, reguladora del Derecho a la Educación (LODE), recoge en su artículo primero los derechos educativos básicos, que son idénticos para nacionales e inmigrantes. En el Artículo segundo, se reconoce que la actividad educativa está orientada a diferentes fines, entre ellos se destaca la formación en el respeto de la pluralidad lingüística y cultural de España. Con esta ley comienza el reconocimiento de la diversidad en los centros educativos. En el Artículo sexto se menciona el derecho a: "Recibir las ayudas y los apoyos precisos para compensar las carencias y desventajas de tipo personal, familiar, económico, social y cultural, (...) que impidan o dificulten el acceso y la permanencia en el sistema educativo". La LODE es la primera ley educativa que cumplió con las expectativas constitucionales.

Cinco años más tarde, en 1990, se aprueba la Ley Orgánica General del Sistema educativo (LOGSE). Esta ley propone medidas concretas para atender a las desigualdades y establece medidas compensatorias, haciendo referencia a la necesidad de atender al alumnado inmigrante y dar respuesta educativa a las diferencias culturales. En esta ley aparecen y se institucionalizan términos como diversidad o inclusión (GARCÍA-CANO; MÁRQUEZ-LEPE; ANTOLÍNEZ-DOMÍNGUEZ, 2016). En 1995 se aprueba la Ley Orgánica de la Participación, la Evaluación y el Gobierno de los Centros Docentes (LOPEG). Este documento incorpora términos 
como pluralidad sociocultural, compensación educativa, escuela integradora o lenguas de acogida. En el ańo 2002, entra en vigor la Ley Orgánica de Calidad (LOCE), la cual no llegó aplicarse tras la llegada a la presidencia del gobierno el Partido Socialista. Esta ley supone un retroceso en lo que se refiere a la democracia en las escuelas y un retroceso para la escolarización del alumnado de procedencia extranjera. Seguidamente, en 2006 se aprueba la Ley Orgánica de educación (LOE), que se caracteriza por establecer como principio básico la atención a la diversidad del alumnado y responder a las demandas educativas sin exclusiones:

Artículo único «b): La equidad, que garantice la igualdad de oportunidades para el pleno desarrollo de la personalidad a través de la educación, la inclusión educativa, la igualdad de derechos y oportunidades que ayuden a superar cualquier discriminación y la accesibilidad universal a la educación, y que actúe como elemento compensador de las desigualdades personales, culturales, económicas y sociales, con especial atención a las que se deriven de cualquier tipo de discapacidad.»

La LOE definió "a la escuela pública como un espacio de convivencia y aprendizaje, que ofrece un servicio que garantiza el derecho a la educación de todos, y que atienda a la diversidad cultural como un elemento educativo de primer orden" (LEIVA; ESCARBAJAL-FRUTOS, 2011, p. 395). Posteriormente, surge la LOMCE (Ley Orgánica 8/2013, de 9 de diciembre, para la mejora de la calidad educativa), que continúa manteniendo el mismo enfoque. Por último, nos referimos al Real Decreto 1105/2014, de 26 de diciembre, por el que se establece el currículo básico de la Educación Secundaria Obligatoria y del Bachillerato (BOLETÍN OFICIAL DEL ESTADO, 3 de enero de 2014). En esta norma, por lo que respecta al currículo de la educación secundaria obligatoria, además de los objetivos relativos al rechazo a la violencia y los prejuicios y a la resolución pacífica de los conflictos contempla, también se contempla el conocimiento, valoración y respeto de la cultura propia y de otras culturas.

Siguiendo directrices de la normativa nacional, cada región tiene capacidad para organizar el sistema educativo dentro de su ámbito geográfico de competencia. Cada región elabora sus propias políticas, por lo cual se ha ido creando una normativa regional muy heterogénea. Algunas regiones se han centrado de manera específica en planes de atención a la diversidad, y en medidas organizativas y curriculares; en cambio, otras regiones han aprobado normas más generales (ARROYO-GONZÁLEZ, 2013). 


\section{Políticas educativas hacia la igualdad de oportunidades, la inclusión y la diversidad}

En 1994, en la Declaración de Salamanca, se acuerda: "Los sistemas educativos deberían ser diseñados para recoger las características y necesidades (...) Las escuelas con esta orientación representan el medio más eficaz para combatir actitudes discriminatorias, creando comunidades de acogida, construyendo una sociedad integradora y logrando educación para todos" (UNESCO, 1994: 2). En España el alumnado inmigrante comenzó incorporándose al sistema educativo a través de un modelo asimilacionista y compensatorio, para evolucionar posteriormente a un enfoque más integral y complejo basado en la inclusión educativa (ESCARBAJAL-FRUTOS, 2010). El término de escuela inclusiva se refiere a una escuela para todos, independientemente de las características y diferencias por motivo de cultura, raza, religión, lengua o capacidad (BARRIODE LA PUENTE, 2008). Según Gómez (2005, p. 204), “surge el reto de atender a toda esta diversidad para prevenir, evitar o reducir el fracaso escolar y todas las formas de exclusión social por marginación, inadaptación y discriminación”.

Desde principios del XXI se han desarrollado políticas educativas para atender a las necesidades del alumnado extranjero. Las medidas planteadas se realizaban con el objetivo de mejorar el proceso de enseñanza-aprendizaje y la inclusión educativa del joven inmigrante. Sin embargo, estas acciones siempre iban encaminadas a la compensación del déficit: enseñanza del español con las aulas de ATAL a principios del 2000; transmisión de la cultura española; características y normas del centro educativo, etc. (GOENECHEA; GARCÍA-FERNÁNDEZ; JIMÉNEZ-GÁMEZ, 2011; MARTÍNEZ-USARRALDE; LLORET-CATALÁ; CÉSPEDES-RICO, 2016). De forma puntual y como actividad ajena al currículum, el profesorado realizaba acciones como la "Semana cultural", en la que se trabajaban las distintas culturas. Estas prácticas no conducen a la profundización y la reflexión sobre la interculturalidad para favorecer el respeto a la diversidad cultural, y normalmente se cae en los prejuicios y estereotipos que abundan en la sociedad (MERINOMATA; LEIVA, 2007). Las prácticas educativas que incluyen las diferentes culturas, lenguas, la diversidad, etc., se englobaban como "interculturales". Sin embargo, se realizan estrategias basadas en la multicultural de los centros, incluso algunas prácticas educativas se caracterizaban por el carácter asimilacionista o etnocéntrico, contrarias a los principios interculturales" (GOENECHEA; GARCÍA-GARCÍA, 2011). Diversas investigaciones plantean la importancia de construir escuelas inclusivas con carácter intercultural que tengan en cuenta las diferencias del alumnado y apuesten por una metodología que valore conocimientos previos, 
valores, ideas y sentimientos del alumnado, reconociendo la diversidad dentro del grupo de clase (ESCARBAJAL-FRUTOS, 2010; GARCÍA-CANO TORRICO, 2016; LEIVA, 2013).

Se debe transformar el imaginario social y desde los centros educativos se debe de abordar la diversidad cultural como un valor que aporta beneficios tanto para el alumnado autóctono como para el alumnado inmigrante: convivencia de diferentes culturas, empatía y respeto a lo diferente (GÓMEZ-JARABO, 2015). En palabras de una profesora de Secundaria (Málaga, España, 2018): "Recibir tantos inmigrantes no tiene por qué ser visto de una manera negativa, yo creo que todo lo contrario. Le tenemos que dar la vuelta, tenemos que decir: 'qué dices, es un lujazo "'. Se trata de contribuir a hacer realidad una escuela abierta a la comunidad, que colabore con el tejido asociativo y con las instituciones para la construcción de una sociedad inclusiva.

En septiembre de 2011, el Consejo de Ministros del gobierno de España aprobó el Plan Estratégico de Ciudadanía e Integración 2011-2014. El principal objetivo del Plan 2011-2014 fue fortalecer la cohesión social, en un contexto migratorio caracterizado por la reducción de flujos de entrada de inmigrantes. Este acuerdo pretendía reforzar tanto los instrumentos y políticas de integración como los servicios públicos y de participación, para garantizar el acceso de todos los ciudadanos en condiciones de igualdad. Este Plan se basó en cuatro principios que inspiran la acción estratégica que se diseńa en este Plan. Los objetivos propuestos fueron:

" $1{ }^{\circ}$ El principio de igualdad y no discriminación, que implica la equiparación de derechos y obligaciones de la población inmigrante y española, dentro del marco de los valores constitucionales básicos.

$2^{\circ}$ El principio de ciudadanía, que implica el reconocimiento de la plena participación cívica, social, económica, cultural y política de los ciudadanos y ciudadanas inmigrantes.

3. ${ }^{\circ}$ El principio de inclusión, que implica la creación de procesos que lleven a superar las desventajas sociales, económicas, personales y culturales y permitan que se esté en condiciones de gozar de los derechos sociales y ejercer la participación ciudadana superando el estatus de persona asistida y la estigmatización que conlleva la pobreza, la marginación y la exclusión.

$4^{\mathrm{o}}$ El principio de interculturalidad, como mecanismo de interacción positiva entre las personas de distintos orígenes y culturas, dentro de la valoración y el respeto de la diversidad cultural". (PLAN ESTRATÉGICO DE CIUDADANÍA E INTEGRACIÓN, 2011, p. 104) 
Con este plan, se pretende trabajar desde la inclusión como término que hace referencia a la actitud positiva de respuesta a la diversidad desde las instituciones educativas. Este Plan implicó un progreso evidente, pues dejó atrás los modelos de exclusión, de segregación y de integración en su versión reduccionista. Según Escarbajal-Frutos (2010), este Plan confirma que la inclusión aparece como un derecho humano indiscutible y como un objetivo prioritario para todos los centros educativos, basado en las comunidades de aprendizaje y en un modelo comunitario de participación social. Las comunidades de aprendizaje son proyectos colaborativos, que incluyen un conjunto de actuaciones dirigidas a la transformación social y educativa (DÍEZ-PALOMAR; FLECHA-GARCÍA, 2010). Para llevar a cabo estos proyectos, se necesita la implicación y motivación de las personas que participan, sobre todo el trabajo del equipo directivo, del profesorado y de las personas voluntarias (ORTEGA-PALACIOS; ÁLVAREZ-ÁLVAREZ, 2015).

\section{Retos para el profesorado de la diversidad intercultural y de la inclusión}

Con el aumento de la inmigración, a veces pueden aumentar los conflictos, sobre todo si la diversidad cultural se considera como un problema. Como se resalta en diferentes investigaciones, "la entrada de alumnado inmigrante en los centros educativos del Estado español durante estas últimas décadas, lejos de lo que se cree, aporta un valor ańadido y una oportunidad para poder interactuar con más diversidad de opiniones y visiones de nuestro entorno" (SAMPÉ-COMPTÉ; ARANDIA; ELBOJ, 2012, p. 13).

"Normalmente siempre te dicen (cuando tienen un índice alto de inmigración) que la problemática que puede existir entre las distintas culturas es grande. Nosotros nos sentimos tremendamente orgullosos, porque nuestras diferentes nacionalidades son como si fuera una. Aquí nadie se mete con nadie por el hecho de ser de otro país. (...) Aquí todos somos diferentes y todos somos iguales". Estas son las palabras de una directora (2018) de un centro educativo de Sevilla (España) donde conviven un total de veintisiete nacionalidades.

Sin embargo, a menudo el profesorado considera que los inmigrantes son un problema en el aula, porque alteran el clima de la clase, dificultan el trabajo y deterioran la calidad de la enseñanza. Esta afirmación no parece correcta, ya que estudios recientes han concluido que la inmigración no constituye un problema escolar y la concentración del alumnado inmigrante en las aulas no incide en el fracaso escolar (ÁLVAREZ DE SOTOMAYOR, 2012); NAVARRO-BARBA, 2015). El profesorado, en ocasiones, tiende a etiquetar al alumnado inmigrante 
de acuerdo a creencias sociales y culturales estereotipadas. Esto puede crear expectativas más bajas en los alumnos inmigrantes, en relación con el alumnado de nivel socioeconómico más aventajado o pertenecientes a la mayoría cultural y étnica. Esto influye negativamente en el desarrollo educativo, de acuerdo con la profecía que se autocumple o "Efecto Pigmalión" (CASTEJÓN-COMPANY, 2017; GÓMEZ-JARABO, 2015).

Según Ipiña (1997, p. 103-104), los docentes que quieran promover la interculturalidad deberán "tener entre sus actitudes habituales (...) deberíamos decir que son auténticas virtudes: 1) su compromiso con las causas de su pueblo y los grupos culturales minoritarios, 2) la tolerancia activa y la estimación de lo diferente, 3) la apertura al mundo y a las innovaciones". Ante esta situación, el profesorado demanda formación para cambiar sus actitudes, valores y prácticas educativas, con el objetivo de favorecer la diversidad (BORRERO-LÓPEZ, 2015). Se hace necesario ncluir la educación intercultural en los planes de estudio universitarios, así como ofertar cursos más prácticos desde los Centros de Formación del Profesorado. Peiró i Grègori y Merma-Molina (2012, p. 137) consideran que "resulta crucial el reciclaje de los profesores respecto a sus posiciones y prácticas para gestionar la diversidad cultural. El profesorado, y no sólo quienes atienden a culturas minoritarias, debe recibir una formación para la elaboración de Proyectos del Centro Interculturales".

La formación en educación intercultural no puede limitarse sólo al profesorado, pues resulta imprescindible sensibilizar y dar a conocer las culturas minoritarias a toda la comunidad educativa. Muchas veces son las propias familias quienes perjudican a los menores, basándose en estereotipos generalizados y exagerados que simplifican al colectivo inmigrante. En palabras de un antiguo director de un centro educativo: "Lo importante no eran los alumnos extranjeros, sino los otros, los aborígenes, los autóctonos, porque claro. Es que claro, el grupo de acogida es el que tiene que conocer." (Málaga, España, 2018).

Resulta conveniente la promoción de actividades para trabajar en colaboración con las familias organizando actividades formativas, campańas y jornadas interculturales, para difundir un mejor conocimiento de la diversidad intercultural y de sus beneficios. De esta forma, el esfuerzo realizado por el profesorado en los centros educativos puede tener continuidad en ámbitos comunitarios y familiares. Así, se puede intervenir para que no aparezcan más noticias como esta: "Los alumnos inmigrantes en España denuncian sufrir más acoso escolar" (Marzo, 2018). El alumnado inmigrante en España está más integrado en la escuela que en la media de los países de la OCDE. Sin embargo, los alumnos de origen inmigrante son cinco puntos porcentuales más propensos que los estudiantes nativos espańoles a denunciar "intimidación frecuente" en el 
ámbito escolar (EUROPA PRESS, 2018). No sólo hay que preocuparse por el rendimiento académico del estudiante; también hay que desarrollar interés hacia su bienestar y desarrollo personal, tanto en la escuela como en la sociedad.

Como propuesta se valora positivamente el trabajo en red para crear un espacio de profesionales comprometidos que puedan compartir conocimientos, preocupaciones y experiencias, centrándose en la mejora y la colaboración (TORNEL-COSTA, 2015). Resulta necesario formar equipos interprofesionales que estén implicados con el colectivo inmigrante, y en los que participen asociaciones, centros educativos, entidades públicas y otros actores sociales relevantes. (DE LA PORTILLA; GONZÁLEZ-MONTEAGUDO, 2013; BORRERO-LÓPEZ, 2015).

\section{Propuestas para trabajar la formación del profesorado, la diversidad y la inclusión en contextos migratorios}

"Deberíamos de reflexionar, ya no sólo desde el punto de vista del aprendizaje puramente académico, sino también...que no dejan de ser personas. Que vienen con su cultura y su mochila. Vamos a entenderlos en toda su plenitud, no solo como alumnos y alumnas" (Profesor de Secundaria, Sevilla, España, 2018). La escuela tiene la función de dotar de recursos para que el alumnado consiga alcanzar el éxito académico, como las aulas ATAL o las adaptaciones curriculares. Los alumnos y menores inmigrantes necesitan comprensión y respeto del duelo migratorio y apoyo para la construcción de la propia identidad, entre el lugar de origen y el lugar de acogida. Los profesores son los encargados de abordar la transición de la enseńanza primaria a la secundaria. Este momento es difícil debido al cambio de centro, el aumento del profesorado y la mayor exigencia académica para todo el alumnado. Los alumnos inmigrantes, junto a todos estos factores, están experimentando las dificultades del proceso migratorio y pueden tener dificultades asociadas a la adaptación cultural, a la lengua, a situaciones familiares complicadas, al rechazo en el aula y al duelo migratorio que están viviendo (ALEMANY-ARREBOLA, 2013; CANO-HILA; SÁNCHEZ-MARTÍ; MASSOT-LAFÓN, 2016).

El derecho a la educación no puede quedar limitado a la garantía de acceso y a la gratuidad de la escolarizada obligatoria, pues es imprescindible atender a las condiciones en las que se desarrolla el proceso de enseñanza-aprendizaje: capacidad, cultura, procedencia, nivel económico-social, etc. (CASTEJÓN-COMPANY, 2017). Siguiendo estudios de López y Sourrouille (2013), las políticas educativas, 
hoy en día, ya no sólo deben perseguir la igualdad de oportunidades educativas, sino también la igualdad en los logros educativos, a fin de que la experiencia escolar garantice el acceso a un conocimiento que habilite a todo el alumnado para su desempeño en la sociedad.

Por tanto, la institución escolar debe constituir un medio esencial para la adquisición de saberes y competencias que posibiliten una integración y participación efectiva, garantizando el ejercicio de los derechos civiles, políticos y sociales (MARTÍNEZ-USARRALDE, LLORET-CATALÁ Y CÉSPEDESRICO, 2016). Para equiparar las condiciones, se deben asignar recursos para mejorar las expectativas de los colectivos menos favorecidos, como el alumnado inmigrante. Estas condiciones son determinantes para "las oportunidades, los resultados y las trayectorias educativas de los jóvenes, por lo que deben situarse en primer plano al abordar la justicia educativa y el derecho a la educación" (CASTEJÓN-COMPANY, 2017, p. 15). El desafío es proponer un modelo de inclusión educativa para el alumnado inmigrante, para construir una escuela que valore a todos los individuos en su condición de ciudadanos (PEIRÓ I GRÈGORI; MERMA-MOLINA, 2012).

Se propone que el profesorado conozca las características y necesidades del alumnado inmigrante de forma más práctica, centrándose en aspectos actitudinales, reflexivos y críticos (BORREGO-LÓPEZ, 2015). El profesorado debe de crear un ambiente de acogida, inclusión y respeto en el aula ordinaria. La formación del profesorado es la pieza clave en la educación intercultural, porque debe estar capacitado para tratar con alumnos de distintas culturas y lenguas, que tienen necesidades diferentes (PEIRÓ I GRĖGORI Y MERMA-MOLINA, 2012). La formación ofrece al profesorado la oportunidad de no repetir estigmas y adaptarse a la realidad de su aula, además de estar en continuo reciclaje personal y transformación de los centros educativos (TORNEL-COSTA, 2015).

La formación del profesorado constituye un elemento fundamental en la mejora de la calidad del sistema (RODRÍGUEZ-GÓMEZ; ARMENGOL; MENESES, 2017). Para conseguir que la formación sea efectiva, debe conllevar un cambio actitudinal y reflexivo que conduzca a la erradicación de estereotipos, prejuicios y conductas discriminatorias hacia el alumnado inmigrante (NAVARRO-BARBA, 2015; TORNEL-COSTA, 2015). Lo importante es dotar al profesorado de las habilidades necesarias para llevar a cabo la tarea educativa en la sociedad del siglo XXI. Según Soriano (2012), la educación no puede tener calidad si no es intercultural.

El objetivo debe ser formar al alumnado de todos los grupos culturales para poder adaptarse, desenvolverse y ser competente tanto el contexto de la cultura de acogida como en su cultura de origen. Esto implica superar los 
enfoques asimilacionistas y reduccionistas (JULIANO, 2002). La verdadera educación intercultural se construye con diálogo y encuentro compartido basado en el respeto y la valoración de alumnado, profesorado, familias, asociaciones y otros actores educativos, mediante una dinámica de participación y de diálogo. Para conseguirlo, el centro educativo se debe de abrir a la sociedad, creando las condiciones óptimas para que las familias, tanto autóctonas como inmigrantes, se involucren en la vida del centro.

No podemos olvidar que la administración educativa tiene una responsabilidad importante, pues debe asegurar que todos los alumnos y menores inmigrantes acudan a la escuela y se involucren en las actividades del centro y de la sociedad. Esto implica el planteamiento de un currículum renovado, con nuevos contenidos relativos al conocimiento de las culturas minoritarias y de su historia (PEIRÓ I GRÈGORI; MERMA-MOLINA, 2012).

\section{Referências}

AGUADED-RAMÍREZ, Eva María; VILAS-BOLAS, Susana; PONCEGONZÁLEZ, Nicolás; RODRÍGUEZ-CÁRDENAS, Antonio, José. ¿Qué características tiene la Educación Intercultural que se diseña y aplica en los centros educativos españoles? Qurriculum, Universidad de La Laguna, v. 23, p. 179-201. 2010.

AGUADO-ODINA, Teresa. Investigación en Educación Intercultural. Revista Educatio Siglo XXI, Múrcia, n. 22, p. 39-57. 2014.

ALEMANY-ARREBOLA, I. El abandono escolar temprano en Melilla. In: López-Belmonte, L. (Coord.). Diversidad cultural y educación intercultural. España, Melilla: GEEPP Ediciones, p. 79-96. 2013.

ÁLVAREZ-SOTOMAYOR, Alberto. El papel del origen nacional y del tiempo de residencia en los etiquetados profesorales de los hijos de inmigrantes en secundaria. Revista de la Asociación de Sociología de la Educación (RASE), v. 8, n. 3, p. 380-395. 2015.

ARROYO-GONZÁLEZ, María José. La enseñanza del español al alumnado inmigrante: análisis de los principales programas en el contexto escolar. Revista educación y futuro digital, Madrid, n. 7, p. 70-92. 2013.

BARRIO DE LA PUENTE, Jose Luis. Hacia una Educación Inclusiva para todos. Revista Complutense de Educación, v. 20, n. 1., p. 13-31. 2009. 
BERNABÉ-VILLODRE, María del Mar. Legislación educativa española e interculturalidad: cambios necesarios. Aportaciones Arbitradas-Revista Educativa Hekademos, v. 13, Año VI, p. 65-75. 2013.

BESALÚ, X. Diversidad cultural y educación. Madrid: Síntesis, Madrid, 2002, 256 p.

TORNEL-COSTA, Nuria. Formación docente del profesorado de Educación Primaria en diversidad cultural. Un elemento clave para la transformación y actualización de los centros educativos. 2015. 343f. Tesis doctoral. Universidad de Murcia, Murcia, España. 2015.

BORRERO-LÓPEZ, Raquel. Estudio prospectivo para una formación intercultural del profesorado en la sociedad del siglo XXI. 2015. 611f. Tesis doctoral. Universidad de Extremadura, Badajoz, España. 2015.

CANO-HILA, Ana Belén; SÁNCHEZ-MARTÍ, Angelina; MASSOT-LAFÓN, María Inés. Factores de riesgo y protección de las trayectorias académicas: voces y miradas del alumnado inmigrante en el contexto del área metropolitana de Barcelona, España. Revista Latinoamericana de Ciencias Sociales, Niñez y Juventud, v. 14, n. 2, p. 1371-1387. 2016.

CASTEJÓN-COMPANY, Alba. Expectativas docentes, agrupamiento del alumnado y segregación escolar. Una etnografía en entornos de alta complejidad social en Cataluña. 2017. 480f. Tesis doctoral. Universidad Autónoma de Barcelona, Barcelona, España. 2017.

DE LA PORTILLA, Alberto; GONZÁLEZ-MONTEAGUDO, José. Formación online y Aprendizaje intercultural en red. En II Seminario científico internacional sobre Formación Didáctica con Tecnologías Web 2.0. Sevilla, España: AFOE y Universidad Pablo de Olavide, p. 66-78. 2013.

DÍEZ-PALOMAR, Javier; FLECHA-GARCÍA, Ramón. Comunidades de Aprendizaje: un proyecto de transformación social y educativa. Revista Interuniversitaria de Formación del Profesorado, v. 24, n. 1, p. 19-30. 2010.

DURÁN-MUÑOZ, R. Migraciones y gestión de la diversidad. RIPS: Revista de Investigaciones Políticas y Sociológica, v. 10, n. 2, p. 131-153. 2011.

EL DIARIO ANDALUCÍA. Familias con doble acento: el 14\% de los nacidos en Andalucía tiene un progenitor extranjero. El diario Andalucía, España, 14 de abril. 2013. Disponible en: https://www.eldiario.es/andalucia/ninos-andalucesprogenitor-extranjero_0_131937529.html 
EL MUNDO. Los inmigrantes tendrán derecho a sanidad en las mismas condiciones que los españoles sin que tengan que empadronarse. El Mundo, España, 17 de julio. 2018. Disponible en: https://www.elmundo.es/espana/2018 /07/17/5b4dca45468aebea0f8b45b9.html

EL PAÍS. España se resiste a pedir ayuda a Europa ante el desafío migratorio. El País, España, 12 de noviembre. 2018. Disponible en: https://elpais.com/ politica/2018/11/11/actualidad/1541960359_906846.html

ESCARBAJAL-FRUTOS, Andrés. La escuela inclusiva en una sociedad pluricultural y la importancia del trabajo colaborativo. Enseñanza \& Teaching, v. 28, n. 2, p. 161-179. 2010.

ESCARBAJAL-FRUTOS, Andrés; MORALES-CÁNOVAS, Ana. Estudio de las competencias interculturales del profesorado en Educación Secundaria. International Journal of Educational Research and Innovation (IJERI), v. 6, p. 146-161. 2016.

ESCARBAJAL-FRUTOS, Andrés; LEIVA, Juan. La necesidad de formar en competencias interculturales como fundamento pedagógico: Un estudio en la región de Murcia (España). Revista de currículum y formación del profesorado, v. 21, n. 1, p. 281-293. 2017.

ESCARBAJAL-FRUTOS, Andrés., SÁNCHEZ-HERNÁNDEZ, Marta. y GUIRO-VIVES, Isabel. Factores determinantes del rendimiento académico de alumnos hijos de inmigrantes y autóctonos de origen extranjero en contextos de exclusión social. Revista sobre la infancia y la adolescencia, v. 9, p. 31-46. 2015.

EUROPAPRESS. Calvo reivindica la identidad "mestiza” de España, a la que considera un "gran pasillo geográfico". Europa Press, España, 1 de agosto. 2018. Disponible en: https://www.europapress.es/cultura/noticia-calvo-reivindica-identidad-mestizaespana-considera-gran-pasillo-geografico-20180801153937.html

EUROPA PRESS. Los alumnos inmigrantes en España denuncian sufrir más acoso escolar y tienen más probabilidades de repetir, según OCDE. Europa Press, España, 19 de Marzo. 2018. Disponible en: https://www.europapress. es/epsocial/igualdad/noticia-alumnos-inmigrantes-denuncian-sufrir-mas-acosoescolar-tienen-mas-probabilidades-repetir-ocde-20180319152303.html

España. Ley 14/1970, de 4 de agosto, General de Educación y Financiamiento de la Reforma Educativa. Boletín Oficial del Estado, núm. 187, de 6 de agosto de 1970, pp. 12525 a 12546. 
España. Ley Orgánica 8/1985, de 3 de julio, reguladora del Derecho a la Educación. Boletín Oficial del Estado, núm. 159, de 04/07/1985, pp. 1-21.

España. Ley Orgánica 2/2006, de 3 de mayo, de Educación (LOE). Boletín Oficial del Estado, núm. 106, de 4 de mayo de 2006, pp. 17158-17207.

España. Ley Orgánica 8/2013, de 9 de diciembre, para la mejora de la calidad educativa (LOMCE). Boletín Oficial del Estado, núm. 295, de 10 de diciembre de 2013, pp. 97858-97921.

España. Ministerio de Trabajo e Inmigración, Dirección General de Integración de los Inmigrantes. Plan Estratégico de Ciudadanía e Integración 2011-2014, España, 296 p. Acceso en: http://extranjeros.mitramiss.gob.es/es/Programas_ Integracion/Plan_estrategico2011/pdf/PECI-2011-2014.pdf

GARCÍA-CANOTORRICO, María; MÁRQUEZ-LEPE, Esther; ANTOLÍNEZ DOMÍNGUEZ, I. Una comunidad de aprendizaje desde el enforque intercultural: Diálogos, emergencias y contradicciones en la práctica escolar. Educación XX1, v. 19, n. 2, p. 251-271, 2016.

GOENECHEA, Cristina. ¿Es la formación del profesorado la clave de la educación intercultural? Revista Española de Pedagogía, v. 66, n. 239, p. 119-136. 2008.

GOENECHEA, Cristina. La escuela pública de la España Multicultural: de privilegios y muros invisibles. Revista Interuniversitaria de Formación del Profesorado, v. 85, n. 30.1, p. 111-119. 2016.

GOENECHEA, Cristina; IGLESIAS-ALFÉREZ, Cristina. Recursos educativos para la atención del alumnado extranjero en Andalucía. Sinéctica revista electrónica de educación, n. 48, p. 1-17. 2016.

GOENECHEA, Cristina; GARCÍA-GARCÍA, María del Carmen. Buenas prácticas en educación intercultural. En Actas del I Congreso Internacional sobre Migraciones en Andalucía, España, Granada: Instituto de Migraciones, 2011, p. 703-711.

GOENECHEA, Cristina; GARCÍA-FERNÁNDEZ, José Antonio; JIMÉNEZGÁMEZ, Rafael Ángel. Los dilemas de la atención educativa a los alumnos inmigrantes recién llegados. Estudio comparativo de los modelos andaluz (ATAL) y madrileño (aulas de enlace). Revista de currículum y formación del profesorado, v. 15, n. 3, 263-278. 2011.

GÓMEZ-FERRI, Javier., GRAU-MUÑOZ, Arantxa., GIULIA-INGELLIS, Anna; JABBAZ, Marcela. Técnicas cualitativas de investigación social. 
Grado de Relaciones Laborales y Recursos Humanos. Departamento de Sociología y Antropología Social. Universidad de Valencia. Acceso en: http:// ocw.uv.es/ciencias-sociales-y-juridicas/tecnicas-cualitativas-de-investigacionsocial/tema_4_la_organizacion_de_la_inv.pdf

GÓMEZ-CANTERO, José Andrés. Educación y creatividad. Estudios sobre Educación, n. 9, p. 79-105. 2005.

GÓMEZ-JARABO, Inmaculada. Formación del profesorado para el tratamiento educativo de los conflictos sobre diversidad cultural y de género. 2015. 707f. Tesis doctoral. Universidad Complutense de Madrid, Madrid, España. 2015.

GUICHOT-MUÑOZ, Elena; GONZÁLEZ-MONTEAGUDO, José. La mediación intercultural inclusiva: Retos de un proyecto europeo colaborativo. En Actas del II Seminario Estatal de Interculturalidad, Comunidad y Escuela "La Educación Intercultural a debate", España, Málaga: Universidad de Málaga. 2015. p. 75-85.

HERNÁNDEZ-AYALA, Hernán; TOBÓN-TOBÓN, Sergio. Análisis documental del proceso de inclusión en la educación. Revista Ra Ximhai, v. 12, n. 6, julio-diciembre, p. 399-420. 2016.

IPIÑA, Enrique. "Condiciones y perfil del docente de educación intercultural bilingüe”. Revista Interamericana de Educación, v. 13, p. 99-109. 1997.

JULIANO, Dolores. Los desafíos de la migración. Antropología, educación e interculturalidad. Anuario de Psicología, Facultat de Psicología Universitat de Barcelona., v. 33, n. 4, p. 487-498. 2002.

KRAINER, Anita; GUERRA, Martha. Interculturalidad y educación. Desafíos docentes. Quito: Flacso Ecuador, 2016. 152 p.

LEIVA, Juan José. La educación intercultural: un compromiso educativo para construir una escuela sin exclusiones. Revista Iberoamericana de Educación, v. 56, n. 1, p. 1-14. 2011.

LEIVA, Juan José; ESCARBAJAL-FRUTOS, Andrés. La participación de las familias inmigrantes como fundamento pedagógico en la construcción de la interculturalidad en la escuela. Educatio Siglo XXI, v. 29, n. 2, p. 389-416. 2011.

LEIVA, Juan José. De la integración a la inclusión: evolución y cambio en la mentalidad del alumnado universitario de educación especial en un contexto 
universitario español. Revista Electrónica "Actualidades Investigativas en Educación”, v. 13, n. 3, marzo-diciembre, p. 1-27. 2013.

LÓPEZ, N; SOURROUILLE, F. Desigualdad, diversidad e información. En: KISILEVSKY, M; ROCA. E. (Coord.). Indicadores, metas y políticas educativas. Organización de Estados Iberoamericanos, Madrid, España. 2000. p. 81-94.

MARTÍNEZ-USARRALDE, María Jesús; LLORET-CATALÁ, Carmen; CÉSPEDES-RICO, Manuel. Lo que hacen mejores las escuelas integradoras de alumnado inmigrante. Pedagogía Social Revista Interuniversitaria, v. 29, p. 41-54. 2017.

MERINO-MATA, David; LEIVA, Juan José. El docente ante la realidad intercultural: análisis de sus actitudes para la comprensión de sus nuevas funciones. El Guiniguada, n. 15-16, p. 195-206. 2007.

MICOLTA-LEÓN, Amparo. Teorías y conceptos asociados al estudio de las migraciones internacionales. Revista del Departamento de Trabajo Social, Facultad de Ciencias Humanas, Universidad Nacional de Colombia, v. 7, p. 59-76. 2005

NAVARRO-BARBA, Juan. Estudio de rendimiento escolar en el alumnado inmigrante y de origen extranjero en la Educación Secundaria de la región de Murcia. 2015. 307f. Tesis doctoral. Universidad de Murcia, Murcia, España. 2015.

NIETO-MERINO, Andrea. El fenómeno migratorio en España en el siglo XXI. 2015. 44f. Trabajo Fin de Grado. Universidad del País Vasco, País Vasco, España. 2015.

ORTEGA-PALACIOS, Iván; ÁLVAREZ-ÁLVAREZ, Carmen. Cuatro años de grupos interactivos: estudio de caso de un centro educativo pionero. EducatioSiglo XXI, v. 33, n. 2, p. 105-122. 2015.

PEIRÓ I GRÈGORY, Salvador; MERMA-MOLINA, Gladys. La interculturalidad en la educación. Situación y fundamentos de la educación intercultural basada en valores. Revista Castellano-Manchega de Ciencias Sociales, v. 13, p. 127-139. 2012.

PEÑALVA-VÉLEZ, Alicia; SORIANO, Encarnación. Objetivos y contenidos sobre interculturalidad en la formación inicial de educadores y educadoras. Estudios sobre educación, 18, 37-57. 2010. 
RODRÍGUEZ-GÓMEZ, David; ARMENGOL, Carme; MENESES, Julio. La adquisición de las competencias profesionales a través de las prácticas curriculares de la formación inicial de maestros. Revista de Educación, n. 376, Abril-Junio, p. 229-251. 2017.

SAMPÉ-COMPTE, Marc; ARANDIA, Maite; ELBOJ, Carmen. Actuaciones educativas que están consiguiendo éxito educativo en centros educativos con alumnado inmigrante. Revista Interuniversitaria de Formación del Profesorado, v. 73, n. 26-1, p. 119-132. 2012.

SORIANO, Encarnación. Planteamiento intercultural del currículum para su calidad educativa. Revista Iberoamericana sobre Calidad, Eficacia y Cambio en Educación, v. 10, n. 4, p. 49-62. 2012.

TORNEL-COSTA, Nuria. Formación docente del profesorado de Educación Primaria en diversidad cultural. Un elemento clave para la transformación y actualización de los centros educativos. 2015.343f. Tesis doctoral. Universidad de Murcia, Murcia, España. 2015. 